\title{
A prospective study of postmenopausal hormone use and ovarian cancer risk
}

\author{
KN Danforth ${ }^{*, 1}$, SS Tworoger, ${ }^{1,2}$, JL Hecht ${ }^{3}$, BA Rosner ${ }^{1,4}$, GA Colditz ${ }^{1,2}$ and SE Hankinson ${ }^{1,2}$ \\ 'Channing Laboratory, Department of Medicine, Brigham and Women's Hospital and Harvard Medical School, Boston, MA, USA; ${ }^{2}$ Department of \\ Epidemiology, Harvard School of Public Health, Boston, MA, USA; ${ }^{3}$ Department of Pathology, Beth-Israel Deaconess Medical Center, Boston, MA, USA; \\ ${ }^{4}$ Department of Biostatistics, Harvard School of Public Health, Boston, MA, USA
}

\begin{abstract}
The relationship between postmenopausal hormone use $(\mathrm{PMH})$ and ovarian cancer risk is unclear, particularly for specific hormone formulations, but recent studies suggest that there is a positive association. We conducted a prospective observational study with 82905 postmenopausal women, including 389 ovarian cancers, in the Nurses' Health Study from 1976 to 2002. Compared with never users of $\mathrm{PMH}$, both current and past users of $\geqslant 5$ years had a significantly elevated risk of ovarian cancer $(\mathrm{RR}=1.4 \mathrm{I}, 95 \%$ confidence interval $(\mathrm{Cl}) 1.07-1.86$ and relative risk $(R R)=1.52,95 \% \mathrm{Cl} 1.01-2.27$, respectively). Examined by hormone type in continuous years, use of unopposed estrogen was associated with a significant increase in the risk of epithelial ovarian cancer $(P$ for trend <0.00।; RR for 5-year increment of use =1.25, 95\% Cl I.12-1.38). Use of estrogen plus progestin (RR for 5-year increment of use $=1.04,95 \% \mathrm{Cl} 0.82-1.32$ ) was not significantly associated with ovarian cancer risk. Generally, results were similar for serous tumours (RR for 5-year increment of unopposed estrogen use $=1.23,95 \% \mathrm{Cl} 1.07-1.40$ ) and slightly stronger for endometrioid tumours (RR for 5 -year increment of unopposed estrogen use $=1.53,95 \% \mathrm{Cl}$ I.20-1.94). Recency of use was not significantly associated with ovarian cancer risk, but statistical power was limited here.
\end{abstract}

British Journal of Cancer (2007) 96, I5I-156. doi: I0.1038/sj.bjc.6603527 www.bjcancer.com

Published online 19 December 2006

(c) 2007 Cancer Research UK

Keywords: hormone; ovarian cancer; postmenopausal; epidemiology

Ovarian cancer is the fifth most common cause of cancer mortality among women in the United States (American Cancer Society, 2006), and yet few truly modifiable factors have been established. Postmenopausal hormone (PMH) use has been examined as a potential risk factor for ovarian cancer in several studies, but reviews (IARC Working Group on the Evaluation of Carcinogenic Risks to Humans et al, 1999; Riman et al, 2004; Farquhar et al, 2005) and meta-analyses (Garg et al, 1998; Coughlin et al, 2000) have found studies to be inconsistent, as did the US Preventive Services Task Force review of higher-quality studies (USPSTF, 2005). Recently, unopposed estrogen use has been positively associated with ovarian cancer risk or mortality in several cohort studies (Rodriguez et al, 2001; Lacey et al, 2002, 2006; Folsom et al, 2004). Although estrogen plus progestin use also has been examined in multiple studies (Lacey et al, 2002, 2006; Riman et al, 2002; Sit et al, 2002), only one cohort study reported a substantial number of cases among long-duration estrogen plus progestin users, finding a significant increased risk of ovarian cancer (Lacey et al, 2006).

We evaluated the association between $\mathrm{PMH}$ use and ovarian cancer in the prospective Nurses' Health Study (NHS) over 26 years of follow-up; we examined duration, recency of use, and

*Correspondence: Dr KN Danforth, Channing Laboratory, I8I Longwood Avenue, 3rd Floor, Boston, MA 02115, USA;

E-mail: kim.danforth@channing.harvard.edu

Received 3 July 2006; revised 13 November 2006; accepted 15 November 2006; published online 19 December 2006
PMH type for all ovarian tumours, as well as by histologic tumour type.

\section{MATERIALS AND METHODS}

\section{Study cohort}

The NHS began in 1976, when 121701 female registered nurses in 11 US states completed a self-administered, mailed questionnaire. At enrolment, participants were 30-55 years old. Subsequently, follow-up questionnaires were mailed biennially to obtain updated exposure and disease information. Information on deaths was obtained through the post office, relatives and linkages with the National Death Index. Through 2002, these methods yielded a follow-up rate of $93.7 \%$ of potential person-years. The study was approved by the Institutional Review Board of Brigham and Women's Hospital.

\section{Study population}

The study population was restricted to postmenopausal women. A validation study in the NHS found self-reported menopause to have high reproducibility (Colditz et al, 1987). Women whose menopausal status was missing, or who reported a hysterectomy without bilateral oophorectomy, contributed person-time from the age at which natural menopause occurred for $90 \%$ of the cohort (54 years for current smokers, 56 years for past or never smokers). 
In 1976, there were 24443 postmenopausal women in the NHS. Participants were excluded if they reported radiation as the reason for menopause $(n=209)$, a bilateral oophorectomy $(n=8506)$, or a diagnosis of cancer other than non-melanoma skin cancer $(n=514)$ before the start of follow-up. Women missing exposure or covariate information $(n=1074)$ were excluded (details below), leaving 14140 eligible women in the baseline population.

Women subsequently entered the study population as they became postmenopausal, provided that radiation or bilateral oophorectomy was not the cause of menopause. Participants were censored at the earliest of: (1) development of ovarian cancer, (2) report of any cancer other than non-melanoma skin cancer, (3) death, or (4) the end of the study period, 6/1/2002. Person-time with missing exposure or covariate information also was excluded. From 1976 to 2002, 82905 postmenopausal women accumulated a total of 966017 person-years.

\section{Postmenopausal hormone use}

PMH use was assessed in every questionnaire. In 1976, users reported their total duration of use. As $72 \%$ of users of a known type reported use of unopposed estrogen in 1978 (when such details were first collected), PMH use in 1976 was classified as unopposed estrogen. This classification probably resulted in a small amount of misclassification of other types of $\mathrm{PMH}$; however, in a sensitivity analysis, we also re-coded PMH use in 1976 to other/unknown type of hormone.

\section{Ovarian cancer}

Incident cases of ovarian cancer were identified through responses to biennial questionnaires or death certificates and confirmed by medical record review. From 1976 to 2002, there were 760 reported cases of postmenopausal ovarian cancer. We were unable to obtain medical records for $71(9.3 \%)$ and did not confirm the diagnosis upon medical record review for $135(17.8 \%)$ women. Of the 554 confirmed cases, 492 were epithelial tumours (88.8\%). After applying exclusion criteria (e.g., prior diagnosis of another cancer), we were left with 389 cases of primary epithelial ovarian cancer.

Histologic type, as coded from pathology reports by a gynecologic pathologist (JLH), had the following distribution: 233 serous/poorly differentiated (hereafter referred to as serous), 60 endometrioid, 35 mucinous, 19 clear-cell and 42 other/unknown subtype. Of the 389 cases, 353 were invasive and 36 were of low malignant potential (18 serous, 15 mucinous, 2 endometrioid and 1 clear cell).

\section{Covariates}

Age and time period were used as stratification variables in the Cox proportional hazards models. Based on previous literature, the following covariates were forced into the multivariate models: duration of oral contraceptive use (continuous), parity (continuous), tubal ligation (yes/no), age at natural menopause (continuous) and age at menarche $(<12,12,13,14, \geqslant 15$ years). The complete case method (restricting the analysis to participants with data on the exposure and all covariates) was used, except that women with a hysterectomy were included; the population was restricted to women with natural menopause in secondary analyses.

In addition, the following potential confounders were not included in the final models: vigorous physical activity, smoking, alcohol consumption, caffeine intake, lactose/galactose consumption, perineal talc use, breastfeeding, simple hysterectomy, use of non-steroidal anti-inflammatory medications other than aspirin and family history of breast cancer. Data on family history of ovarian cancer, first collected in 1992, was evaluated as a potential confounder by examining its distribution across PMH categories in 1992. Fat intake and body mass index (BMI) were not considered confounders because they were not associated with postmenopausal ovarian cancer in previous NHS analyses (Bertone et al, 2002; Fairfield et al, 2002). However, BMI and having an intact reproductive system (no tubal ligation or hysterectomy) were evaluated as potential effect modifiers.

\section{Data analysis}

Multivariate Cox proportional hazards regression models were used to estimate RRs and $95 \%$ CIs. The association with ovarian cancer was examined for status of $\mathrm{PMH}$ use (never, past and current), total duration and time since last use. In addition, analyses were performed by type-specific duration in continuous years, simultaneously including all $\mathrm{PMH}$ types in the models (unopposed estrogen, estrogen plus progestin, other $\mathrm{PMH}$ ). Results have not been presented for the 'other $\mathrm{PMH}$ ' group because it represents a heterogeneous group of hormones, including non-conjugated estrogens, patch hormones, and vaginal hormones, as well as person-time for which hormone type was not reported.

Primary analyses included all tumours (invasive and low malignant potential), but sensitivity analyses restricted cases to invasive tumours. Separate analyses were performed for serous and endometrioid tumour subtypes, but owing to small numbers, those for mucinous tumors $(n=35)$ were adjusted only for age, and clear cell tumors $(n=19)$ were not evaluated.

\section{RESULTS}

\section{Description of the study population}

Population characteristics are presented for 1992 (Table 1), the approximate midpoint of the study, and the first year in which family history of ovarian cancer was collected. The mean age among study participants in 1992 was 61.2 years. The average duration of hormone use was longer among current unopposed estrogen users than current estrogen plus progestin users (9 vs 6 years, respectively). Compared to never users, $\mathrm{PMH}$ users were more likely to have used oral contraceptives or had a simple hysterectomy. As expected, current users of unopposed estrogen were substantially more likely to have had a hysterectomy than current users of estrogen plus progestin. Correspondingly, tubal ligation was more common among users of estrogen plus progestin than users of unopposed estrogen. The distribution of other risk factors was generally similar across PMH classifications. There was no substantial variation by family history of ovarian cancer across exposure groups.

\section{Multivariate results}

Results from the age-adjusted and multivariate models were nearly identical, indicating minimal confounding by other risk factors (Table 2). Neither current $(\mathrm{RR}=1.24,95 \%$ CI $0.97-1.59)$ nor past $(\mathrm{RR}=1.00,95 \% \mathrm{CI} 0.77-1.31)$ use of $\mathrm{PMH}$ was significantly associated with ovarian cancer risk compared with never use. For serous tumours, current use of $\mathrm{PMH}$ was associated with a significant increase in risk $(R R=1.43,95 \%$ CI 1.04-1.96) compared to never use. Risk was non-significantly increased for endometrioid tumors for current $(\mathrm{RR}=1.61,95 \% \mathrm{CI} 0.85-3.05)$ and past $(\mathrm{RR}=1.68,95 \% \mathrm{CI} 0.85-3.33)$ use compared with never use. Results were similar when models were restricted to invasive tumours (data not shown).

When analyses were stratified by total duration of PMH use $(<5$ and $\geqslant 5$ years), increased risk was observed among both current $(\mathrm{RR}=1.41,95 \% \mathrm{CI} 1.07-1.86)$ and past $(\mathrm{RR}=1.52,95 \% \mathrm{CI} 1.01-$ 
Table I Age and age-standardised characteristics by postmenopausal hormone use and hormone type in the Nurses' Health Study, $1992^{2}$

\begin{tabular}{|c|c|c|c|c|c|}
\hline & \multicolumn{3}{|c|}{ PMH status } & \multicolumn{2}{|c|}{ Current PMH users } \\
\hline & $\begin{array}{l}\text { Never user } \\
(n=20853)\end{array}$ & $\begin{array}{c}\text { Past user } \\
(n=10053)\end{array}$ & $\begin{array}{l}\text { Current user } \\
(n=16831)\end{array}$ & $\begin{array}{l}\text { Estrogen only } \\
\quad(n=4315)\end{array}$ & $\begin{array}{l}\text { Estrogen+Progestin } \\
\quad(n=7394)\end{array}$ \\
\hline Age, mean, years & 61 & 64 & 60 & 62 & 58 \\
\hline Duration of PMH use, mean, years & 0 & 3 & 7 & 9 & 6 \\
\hline \multicolumn{6}{|l|}{ Duration of OC use (\%) } \\
\hline$\geqslant 3$ years & 17 & 20 & 23 & 23 & 26 \\
\hline \multicolumn{6}{|l|}{ Parity } \\
\hline Parous women (\%) & 94 & 93 & 93 & 94 & 93 \\
\hline Mean no. of children (among parous) & 3 & 3 & 3 & 3 & 3 \\
\hline Family ${ }^{\mathrm{b}}$ history of ovarian cancer (\%) & 3 & 3 & 2 & 3 & 3 \\
\hline Had a simple hysterectomy (\%) & 5 & 12 & 19 & 47 & 2 \\
\hline
\end{tabular}

Abbreviations: PMH, postmenopausal hormone; OC, oral contraceptive. ${ }^{a}$ Characteristics are presented for the 47737 nurses who met the study eligibility criteria in $1992 ;$ all factors except age were age-standardised in 5-year intervals. 'Mother or sister had ovarian cancer according to nurse's response to questionnaire.

Table 2 Use of postmenopausal hormones and epithelial ovarian cancer risk; all cases combined and by histologic type ${ }^{a}$

\begin{tabular}{|c|c|c|c|}
\hline & Never user & Past user & Current user \\
\hline \multicolumn{4}{|c|}{ All epithelial ovarian tumours } \\
\hline No. of cases & 167 & 88 & 134 \\
\hline Person-years & 455200 & 210778 & 300039 \\
\hline $\begin{array}{l}\text { Age-adjusted RR } \\
(95 \% \mathrm{Cl})\end{array}$ & 1.00 (referent) & $1.00(0.77,1.31)$ & $1.23(0.97,1.57)$ \\
\hline $\begin{array}{l}\text { Multivariate }{ }^{\mathrm{b}} \mathrm{RR} \\
(95 \% \mathrm{Cl})\end{array}$ & 1.00 (referent) & $1.00(0.77,1.31)$ & $1.24(0.97,1.59)$ \\
\hline \multicolumn{4}{|l|}{ Serous tumours } \\
\hline $\begin{array}{l}\text { No. of cases } \\
\text { Multivariate }{ }^{\text {b R }} \\
(95 \% \mathrm{Cl})\end{array}$ & $\begin{array}{c}96 \\
1.00 \text { (referent) }\end{array}$ & $\begin{array}{c}51 \\
0.98(0.69,1.40)\end{array}$ & $\begin{array}{c}86 \\
1.43(1.04,1.96)\end{array}$ \\
\hline \multicolumn{4}{|l|}{ Endometrioid tumours } \\
\hline $\begin{array}{l}\text { No. of cases } \\
\text { Multivariate }{ }^{\text {b R }} \\
(95 \% \mathrm{Cl})\end{array}$ & $\begin{array}{c}21 \\
1.00 \text { (referent) }\end{array}$ & $\begin{array}{c}16 \\
1.68(0.85,3.33)\end{array}$ & $\begin{array}{c}23 \\
1.61(0.85,3.05)\end{array}$ \\
\hline
\end{tabular}

Abbreviations: $\mathrm{RR}$, relative risk; $\mathrm{Cl}$, confidence interval. ${ }^{a}$ Results by histologic type are presented for serous/poorly differentiated and endometrioid tumors only due to small numbers for the other histologic types. ${ }^{b}$ Adjusted for: age, parity, duration of oral contraceptive use, tubal ligation, age at natural menopause, age at menarche.

2.27) users of five or more years compared with never users (Table 3). Results were similar for serous tumors, although statistically significant only for current users of greater than five years $(\mathrm{RR}=1.66,95 \% \mathrm{CI} 1.17-2.36)$. Results generally were stronger for endometrioid tumours, although the increased risk was statistically significant for past $(R R=3.59,95 \%$ CI $1.41-9.14)$, but not current $(\mathrm{RR}=1.86,95 \% \mathrm{CI} 0.89-3.91)$, users of 5 or more years compared with never users.

Combining current and past use, continuous years of unopposed estrogen use were significantly associated with increased risk ( $P$ for trend $<0.001, \mathrm{RR}=1.25$ for a 5 -year increment of use, $95 \%$ CI 1.12-1.38), whereas continuous years of estrogen plus progestin use were not $(P$ for trend $=0.77, \mathrm{RR}=1.04$ for a 5 -year increment of use, 95\% CI $0.82-1.32$ ) (Table 4). Results were similar when hormone use in 1976 was re-classified as unknown/other type (data not shown) and when terms were added for past and current use (data not shown). The increased risk observed with continuous years of unopposed estrogen use was generally similar for serous tumours ( $R R$ for 5-year increment of unopposed estrogen use $=1.23,95 \%$ CI $1.07-1.40)$ and slightly stronger for endometrioid tumours (RR for 5-year increment of unopposed estrogen use $=1.53$, 95\% CI 1.20-1.94), although there was a limited number of cases for the endometrioid analysis. When mucinous tumours were examined in age-adjusted analyses, point estimates suggested that past $(R R=0.72,95 \%$ CI $0.30-1.76)$ and current $(\mathrm{RR}=0.72,95 \% \mathrm{CI} 0.31-1.67)$ users had a reduced risk compared with never users, although results were not significant and based on few cases.

In analyses restricted to women exclusively using one hormone formulation, unopposed estrogen use of five or more years was associated with an increased risk compared with never use $(\mathrm{RR}=2.04,95 \% \mathrm{CI} 1.41-2.97)$, whereas estrogen plus progestin use of five or more years was not $(\mathrm{RR}=0.93,95 \%$ CI $0.47-1.83)$ (Table 5). However, there were only ten cases among estrogen plus progestin users of $\geqslant 5$ years. Results were similar for unopposed estrogen use among women reporting a hysterectomy and estrogen plus progestin use among women with intact uteri (data not shown).

Time since last use was not significantly associated with risk. Neither users who quit within the previous three years $(R R=1.04$, 95\% CI $0.71-1.53$ ) nor those who stopped over three years ago $(\mathrm{RR}=0.86,95 \% \mathrm{CI} 0.60-1.22)$ were at a significantly increased risk of ovarian cancer. Based on the significant association observed with duration, a recency effect would most likely be seen primarily among long-term users. Although limited by small numbers, when we examined the effects of recency and duration together, point estimates suggested an increase in risk among users of five or more years that decreased over time $(R R=1.62$ among the most recent quitters and $\mathrm{RR}=1.35$ among those who quit over 3 years ago, with 17 and 11 cases respectively).

No substantial differences were observed when stratifying on BMI $\left(<25,25-29, \geqslant 30 \mathrm{~kg} \mathrm{~m}^{-2}\right)$ or an intact reproductive system (i.e., no prior hysterectomy or tubal ligation) (data not shown). Results were also similar among women reporting natural menopause, although the association with unopposed estrogen use was slightly stronger ( $R R=1.40$ for a 5 -year increment of use, 95\% CI $1.09-1.80$ ). 
Table 3 Total duration of postmenopausal hormone use and risk of epithelial ovarian cancer; all cases combined and by histologic type ${ }^{a}$

\begin{tabular}{|c|c|c|}
\hline & Never user & $<5$ years us \\
\hline \multicolumn{3}{|l|}{ All epithelial ovarian tumours } \\
\hline No. of cases & 167 & 57 \\
\hline Person-years & 455200 & 164558 \\
\hline Age-adjusted RR $(95 \% \mathrm{Cl})$ & 1.00 (referent) & $0.87(0.64,1.1$ \\
\hline Multivariate ${ }^{b}$ RR $(95 \% \mathrm{Cl})$ & 1.00 (referent) & $0.88(0.64,1.1$ \\
\hline \multicolumn{3}{|l|}{ Serous tumours } \\
\hline No. of cases & 96 & 32 \\
\hline Multivariate $^{\mathrm{b}}$ RR (95\% Cl) & 1.00 (referent) & $0.83(0.55,1.2$ \\
\hline \multicolumn{3}{|l|}{ Endometrioid tumours } \\
\hline No. of cases & & \\
\hline Multivariate $^{\mathrm{b}} \mathrm{RR}(95 \% \mathrm{Cl})$ & 1.00 (referent) & $1.25(0.56,2.8$ \\
\hline \multicolumn{3}{|c|}{$\begin{array}{l}\text { Abbreviations: } \mathrm{RR} \text {, relative risk; } \mathrm{Cl} \text {, confidence interval. }{ }^{\text {a }} \text { Results by histologic type ar } \\
\text { numbers for the other histologic types. }{ }^{\text {Ad }} \text { djusted for age, parity, duration of oral } \mathrm{c}\end{array}$} \\
\hline \multicolumn{3}{|c|}{$\begin{array}{l}\text { Table } 4 \text { Continuous years of estrogen and estrogen plus progestin use } \\
\text { and risk of epithelial ovarian cancer; all cases combined and by histologic } \\
\text { type }{ }^{\text {a }}\end{array}$} \\
\hline & \multicolumn{2}{|c|}{$\begin{array}{l}\text { Continuous RR converted to } 5 \text {-year } \\
\text { increment }\end{array}$} \\
\hline & Estrogen only & $\begin{array}{l}\text { Estrogen plus } \\
\text { progestin }\end{array}$ \\
\hline \multicolumn{3}{|l|}{ All ovarian tumours } \\
\hline Cases $^{b}$ & 137 & 82 \\
\hline Age-adjusted RR (95\% Cl) & $1.23(1.11,1.35)$ & $1.05(0.82,1.33)$ \\
\hline Multivariate $^{c}$ RR $(95 \% \mathrm{Cl})$ & $1.25(1.12,1.38)$ & $1.04(0.82,1.32)$ \\
\hline \multicolumn{3}{|l|}{ Serous tumours } \\
\hline Cases $^{b}$ & 89 & 49 \\
\hline Multivariate $^{c}$ RR $(95 \% \mathrm{Cl})$ & $1.23(1.07,1.40)$ & $1.12(0.84,1.51)$ \\
\hline \multicolumn{3}{|l|}{ Endometrioid tumours } \\
\hline Cases $^{b}$ & 23 & 15 \\
\hline Multivariate ${ }^{c}$ RR $(95 \%$ Cl) & $1.53(1.20,1.94)$ & $1.04(0.53,2.03)$ \\
\hline
\end{tabular}

Past user

Current user

Abbreviations: $\mathrm{RR}$, relative risk; $\mathrm{Cl}$, confidence interval; $\mathrm{PMH}$, postmenopausal hormone. ${ }^{a}$ Results by histologic type are presented for serous/poorly differentiated and endometrioid tumours only due to small numbers for the other histologic types. ${ }^{b}$ Some participants (and therefore cases) contribute to multiple categories simultaneously because they used estrogen only, estrogen plus progestin and/or other PMH formulations. 'Adjusted for age, parity, duration of oral contraceptive use, tubal ligation, age at natural menopause and age at menarche.

\section{DISCUSSION}

In this prospective study, we observed a positive association between long duration of $\mathrm{PMH}$ use and ovarian cancer risk, regardless of whether use was current or past. More specifically, duration of unopposed estrogen use was positively associated with risk, whereas estrogen plus progestin use was not; the association was stronger for endometrioid tumours, although numbers were small.

In a collaborative re-analysis of 12 case-control studies, no association was found with duration of $\mathrm{PMH}$ use in either hospitalbased $(\mathrm{OR}=0.90$ for a 5-year increment of use, $P=0.37)$ or population-based $(\mathrm{OR}=1.10$ for a 5 -year increment of use, $P=0.21$ ) studies (Whittemore et al, 1992). Meta-analyses (Garg et al, 1998; Coughlin et al, 2000) and certain case-control studies (Weiss et al, 1982; Riman et al, 2002) also failed to find a significant trend with duration of use, although some found a

positive association (Risch, 1996) or suggested a positive trend (Kaufman et al, 1989; Bosetti et al, 2001).

Recently, four prospective studies found that longer durations of $\mathrm{PMH}$ use were associated with ovarian cancer risk or death (Rodriguez et al, 2001; Lacey et al, 2002; Folsom et al, 2004; Lacey et al, 2006). In two, ovarian cancer risk (Lacey et al, 2006) and mortality (Rodriguez et al, 2001) were increased among unopposed estrogen users of $\geqslant 10$ years but not among users of $<10$ years; elevations in mortality were similar for current and past long-duration users (Rodriguez et al, 2001). Two other cohort studies observed increases in risk with shorter durations of use: in the Breast Cancer Detection Demonstration Project (BCDDP, $n=329$ cases), unopposed estrogen use was significantly associated with risk $(\mathrm{RR}=1.40$ for 5 years use, converted from a 1year estimate), with similar results for recent and former long-duration users (Lacey et al, 2002). In another prospective study, current users of unopposed estrogens for $>5$ years had a significantly elevated risk $(\mathrm{RR}=2.53,95 \%$ CI $1.44-4.45, n=16$ cases); although risk was not increased among long-duration past users, there were only four cases (Folsom et al, 2004). Findings from recent case-control studies also generally support a positive association with long-duration $\mathrm{PMH}$ use (Glud et al, 2004; Mills et al, 2004; Pike et al, 2004; Riman et al, 2004; Moorman et al, 2005).

We found a strong association with duration of $\mathrm{PMH}$ use and risk among current and past users of five or more years duration. With both duration and status of use (never, past, current) in the same model, only duration was statistically significant (data not shown). Overall, the significant increase in risk appeared to be driven largely by duration rather than by status of use. This contrasts with breast cancer PMH findings, where the increased risk is confined to current users (Colditz et al, 1995; Collaborative Group on Hormonal Factors in Breast Cancer, 1997; Beral et al., 2003), although the comparison is limited by the relative paucity of data on recency effects for ovarian cancer.

Only recently have studies had sufficient case numbers to evaluate associations for estrogen and progestin use. A Swedish case-control study ( $n=655$ cases) found that use of estrogen plus sequential progestin was associated with an increased risk, whereas estrogen plus continuous progestin was not (Riman et al, 2002). However, results from the women's health initiative (WHI), a randomized clinical trial of estrogen plus continuous progestin ( $n=32$ cases), were consistent with an increase in risk ( $\mathrm{RR}=1.58$, 95\% CI $0.77-3.24$ ), although not statistically significant (Anderson et al, 2003). Another cohort study found an increased risk associated with both sequential $(\mathrm{RR}=3.09,95 \%$ CI $1.68-5.68$; 
Table 5 Risk of epithelial ovarian cancer among exclusive users of one hormone type (estrogen only and estrogen plus progestin)

\begin{tabular}{|c|c|c|c|c|}
\hline & \multicolumn{2}{|c|}{ Estrogen only ${ }^{a}$} & \multicolumn{2}{|c|}{ Estrogen plus progestin ${ }^{a}$} \\
\hline & $<5$ years use & $\geqslant 5$ years use & $<5$ years use & $\geqslant 5$ years use \\
\hline \multicolumn{5}{|l|}{ All epithelial ovarian tumours } \\
\hline No. of cases & 39 & 43 & 22 & 10 \\
\hline Age-adjusted $(95 \% \mathrm{Cl})$ & $0.94(0.66,1.34)$ & $1.81(1.28,2.56)$ & $1.03(0.64,1.67)$ & $0.92(0.47,1.79)$ \\
\hline Multivariate $^{b}$ RR $(95 \% \mathrm{Cl})$ & $0.98(0.68,1.40)$ & $2.04(1.41,2.97)$ & $1.03(0.64,1.66)$ & $0.93(0.47,1.83)$ \\
\hline
\end{tabular}

$n=13$ cases $)$ and continuous $(\mathrm{RR}=1.82,95 \% \mathrm{CI} 1.03-3.23 ; n=15$ cases) estrogen plus progestin use of $\geqslant 5$ years in women without a hysterectomy (Lacey et al, 2006).

In contrast, a cohort study in Norway found no association with use of estrogen plus progestin ( $\mathrm{RR}=1.5,95 \% \mathrm{CI} 0.9-2.6 ; n=23$ cases) (Bakken et al, 2004), and nor did the BCDDP study. Data suggested that unopposed estrogen, followed by estrogen plus progestin, was associated with risk; however, the effects of the different hormones could not be disentangled (Lacey et al., 2002). In our study, when simultaneously including terms for years of unopposed estrogen, estrogen plus progestin and other PMH use, only unopposed estrogen use was significantly associated with risk; results were consistent among users of a single hormone type. However, duration of estrogen plus progestin use was on an average shorter than use of unopposed estrogen, and the upper confidence limits were similar to those observed for unopposed estrogen use. Further studies about long-duration estrogen plus progestin use are therefore needed, given its more recent introduction to the market, particularly those focused on sequential or continuous hormone regimens.

Among the few analyses by histologic type, one suggested that $\mathrm{PMH}$ use might specifically increase risk of endometrioid tumours (Weiss et al, 1982). Other prospective studies either have not examined tumour subtype (Rodriguez et al, 2001; Anderson et al, 2003; Bakken et al, 2004; Folsom et al, 2004; Lacey et al, 2006) or had incomplete information on histology (Lacey et al, 2002). Despite limited power, in our study, the association with unopposed estrogen use appeared slightly stronger for endometrioid tumours. In age-adjusted analyses, point estimates suggested $\mathrm{PMH}$ use might decrease the risk of mucinous tumours, consistent with some (Weiss et al, 1982; Risch, 1996), but not all (Riman et al, 2002), previous reports. Although statistical comparisons between the subtypes were precluded by sample size, our findings are consistent with epidemiologic and biologic data. Endometrioid tumours are histologically similar to endometrial tissue (Kumar et al, 1997), and unopposed estrogen use increases the risk of endometrial cancer (Fraser et al, 1998). Mucinous tumors are subclassified as those that resemble colonic or endocervical epithelium (Kumar et al, 1997). PMH use has been associated with decreased colon cancer risk (Nelson et al, 2002) but not with altered cervical cancer risk (Weiss and Hill, 1996).

The mechanism by which PMH might affect ovarian cancer risk is unknown. One theory posits that high levels of gonadotropins increase risk, implying that PMH use might decrease risk by reducing these levels (follicle-stimulating hormone (FSH) and leutinising hormone (LH)), but as the declines associated with PMH use are small, the benefits might be outweighed by estrogeninduced proliferation of ovarian cells (Cramer and Welch, 1983; Fraser et al, 1998); it has been estimated that as many as $60 \%$ of ovarian tumours are estrogen receptor-positive (Cunat et al, 2004). Breast cancer research also suggests that estrogen may be directly genotoxic (Ho, 2003). Although it is premature to conclude that estrogen plus progestin use is unassociated with ovarian cancer risk, particularly given the conflicting findings, research on ovulating macaques suggests that progesterone offsets the effect of unopposed estrogen use by increasing apoptosis in the ovary (Rodriguez et al, 1998), possibly by altering levels of TGF- $\beta$, a regulator of apoptosis (Rodriguez et al, 2002). The progesterone in these animal studies may have different effects from the progestins commonly used in $\mathrm{PMH}$ formulations, but a mechanism is suggested, given that progesterone receptors are normally found in ovarian epithelium (Risch, 1998).

Our analysis has several strengths. The NHS is one of only a few prospective studies of $\mathrm{PMH}$ use and ovarian cancer, and associations could be examined by hormone type. Information on exposures and confounders is updated through biennial questions, and follow-up of the cohort is high. The nurses are a relatively homogenous group, with similar education and access to health care, reducing concerns about confounding. Although family history of ovarian cancer was first collected in 1992, this did not vary substantially across exposure. Histologic tumour type was coded by a gynecologic pathologist and was available for most cases.

Nurses' Health Study (NHS) participants are not a representative sample of the general population. While it is unlikely that the observed associations would differ in other women, studies covering different race/ethnicity and socioeconomic status are warranted. Generalisability may also be limited by the variations in $\mathrm{PMH}$ formulations across countries. We had limited power to look at non-oral formulations of $\mathrm{PMH}$, which are more commonly used outside the US (Ho, 2003). Small numbers prevented evaluation of different regimens of estrogen plus progestin and limited the analysis of recency of use.

In conclusion, we found that use of $\mathrm{PMH}$ was positively associated with risk of epithelial ovarian cancer. With other recent studies, our findings suggest that women should be counseled about the potential long-term increase in ovarian cancer risk with extended use of unopposed estrogen. Evidence is insufficient to say whether estrogen plus progestin or very short durations of unopposed estrogen use are associated with risk. Available findings indicate that ovarian cancer is one of several conditions that should be considered by women when weighing the risk and benefits of $\mathrm{PMH}$ use.

\section{ACKNOWLEDGEMENTS}

The research for this article was funded by the grant CA87969 from the National Institutes of Health. Dr Danforth and Dr Tworoger were supported in part by the National Cancer Institute Training grant, CA09001, in cancer epidemiology. Dr Colditz was supported in part by the American Cancer Society Cissy Hornung Clinical Research Professorship. Dr Hankinson was supported in part by the grant CA105009 from the National Institutes of Health. 


\section{REFERENCES}

American Cancer Society (2006) Cancer Facts \& Figures. American Cancer Society Inc: Atlanta

Anderson GL, Judd HL, Kaunitz AM, Barad DH, Beresford SA, Pettinger M, Liu J, McNeeley SG, Lopez AM (2003) Effects of estrogen plus progestin on gynecologic cancers and associated diagnostic procedures: the Women's Health Initiative randomized trial. JAMA 290: 1739-1748

Bakken K, Alsaker E, Eggen AE, Lund E (2004) Hormone replacement therapy and incidence of hormone-dependent cancers in the Norwegian Women and Cancer study. Int J Cancer 112: $130-134$

Beral V, Million Women Study Collaborators (2003) Breast cancer and hormone-replacement therapy in the Million Women Study. Lancet 362: $419-427$

Bertone ER, Rosner BA, Hunter DJ, Stampfer MJ, Speizer FE, Colditz GA, Willett WC, Hankinson SE (2002) Dietary fat intake and ovarian cancer in a cohort of US women. Am J Epidemiol 156: 22-31

Bosetti C, Negri E, Franceschi S, Trichopoulos D, Beral V, La Vecchia C (2001) Relationship between postmenopausal hormone replace ment therapy and ovarian cancer. [comment]. JAMA 285: 3089; discussion 3090

Colditz GA, Hankinson SE, Hunter DJ, Willett WC, Manson JE, Stampfer MJ, Hennekens C, Rosner B, Speizer FE (1995) The use of estrogens and progestins and the risk of breast cancer in postmenopausal women. $N$ Engl J Med 332: $1589-1593$

Colditz GA, Stampfer MJ, Willett WC, Stason WB, Rosner B, Hennekens $\mathrm{CH}$, Speizer FE (1987) Reproducibility and validity of self-reported menopausal status in a prospective cohort study. Am J Epidemiol 126: $319-325$

Collaborative Group on Hormonal Factors in Breast Cancer (1997) Breast cancer and hormone replacement therapy: collaborative reanalysis of data from 51 epidemiological studies of 52705 women with breast cancer and 108411 women without breast cancer. Lancet 350: 1047-1059

Coughlin SS, Giustozzi A, Smith SJ, Lee NC (2000) A meta-analysis of estrogen replacement therapy and risk of epithelial ovarian cancer. J Clin Epidemiol 53: $367-375$

Cramer DW, Welch WR (1983) Determinants of ovarian cancer risk. II. Inferences regarding pathogenesis. J Natl Cancer Inst 71: 717-721

Cunat S, Hoffmann P, Pujol P (2004) Estrogens and epithelial ovarian cancer. Gynecol Oncol 94: 25-32

Fairfield KM, Willett WC, Rosner BA, Manson JE, Speizer FE, Hankinson SE (2002) Obesity, weight gain, and ovarian cancer. Obstet Gynecol 100: $288-296$

Farquhar CM, Marjoribanks J, Lethaby A, Lamberts Q, Suckling JA (2005) Long term hormone therapy for perimenopausal and postmenopausal women. Cochrane Database Syst Rev, CD004143

Folsom AR, Anderson JP, Ross JA (2004) Estrogen replacement therapy and ovarian cancer. Epidemiology 15: $100-104$

Fraser IS, Jansen RPS, Lobo RA, Whitehead MI (1998) Estrogens and Progestogens in Clinical Practice. Churchill Livingstone: London, New York

Garg PP, Kerlikowske K, Subak L, Grady D (1998) Hormone replacement therapy and the risk of epithelial ovarian carcinoma: a meta-analysis. Obstet Gynecol 92: 472 - 479

Glud E, Kjaer SK, Thomsen BL, Hogdall C, Christensen L, Hogdall E, Bock JE, Blaakaer J (2004) Hormone therapy and the impact of estrogen intake on the risk of ovarian cancer. Arch Intern Med 164: 2253-2259

Ho SM (2003) Estrogen, Progesterone and Epithelial Ovarian Cancer. Reprod Biol Endocrinol 1: 73

IARC Working Group on the Evaluation of Carcinogenic Risks to Humans, International Agency for Research on Cancer, World Health Organization (1999) Hormonal Contraception and Post-Menopausal Hormonal Therapy. IARC Monographs on the Evaluation of Carcinogenic Risks to Humans; vol. 72. IARC; Distributed by IARC Press and the World Health Organization Distribution and Sales: Lyon, France, Geneva
Kaufman DW, Kelly JP, Welch WR, Rosenberg L, Stolley PD, Warshauer ME, Lewis J, Woodruff J, Shapiro S (1989) Noncontraceptive estrogen use and epithelial ovarian cancer. Am J Epidemiol 130: 1142-1151

Kumar V, Cotran RS, Robbins SL (1997) Basic Pathology 6th edn, W.B. Saunders: Philadelphia

Lacey Jr JV, Brinton LA, Leitzmann MF, Mouw T, Hollenbeck A, Schatzkin A, Hartge P (2006) Menopausal hormone therapy and ovarian cancer risk in the National Institutes of Health-AARP Diet and Health Study Cohort. J Natl Cancer Inst 98: 1397-1405

Lacey Jr JV, Mink PJ, Lubin JH, Sherman ME, Troisi R, Hartge P, Schatzkin A, Schairer C (2002) Menopausal hormone replacement therapy and risk of ovarian cancer. [comment][erratum appears in JAMA 2002 Nov 27; 288(20): 2544]. JAMA 288: $334-341$

Mills PK, Riordan DG, Cress RD (2004) Epithelial ovarian cancer risk by invasiveness and cell type in the Central Valley of California. Gynecol Oncol 95: 215-225

Moorman PG, Schildkraut JM, Calingaert B, Halabi S, Berchuck A (2005) Menopausal hormones and risk of ovarian cancer. Am J Obstet Gynecol 193: $76-82$

Nelson HD, Humphrey LL, Nygren P, Teutsch SM, Allan JD (2002) Postmenopausal hormone replacement therapy: scientific review. JAMA 288: $872-881$

Pike MC, Pearce CL, Peters R, Cozen W, Wan P, Wu AH (2004) Hormonal factors and the risk of invasive ovarian cancer: a population-based casecontrol study. Fertil Steril 82: 186-195

Riman T, Dickman PW, Nilsson S, Correia N, Nordlinder H, Magnusson CM, Weiderpass E, Persson IR (2002) Hormone replacement therapy and the risk of invasive epithelial ovarian cancer in Swedish women. J Nat Cancer Inst 94: 497-504

Riman T, Nilsson S, Persson IR (2004) Review of epidemiological evidence for reproductive and hormonal factors in relation to the risk of epithelial ovarian malignancies. Acta Obstet Gynecol Scand 83: 783-795

Risch HA (1996) Estrogen replacement therapy and risk of epithelial ovarian cancer. Gynecol Oncol 63: 254-257

Risch HA (1998) Hormonal etiology of epithelial ovarian cancer, with a hypothesis concerning the role of androgens and progesterone. J Nat Cancer Inst 90: 1774-1786

Rodriguez C, Patel AV, Calle EE, Jacob EJ, Thun MJ (2001) Estrogen replacement therapy and ovarian cancer mortality in a large prospective study of US women. [comment]. JAMA 285: 1460-1465

Rodriguez GC, Nagarsheth NP, Lee KL, Bentley RC, Walmer DK, Cline M, Whitaker RS, Isner P, Berchuck A, Dodge RK, Hughes CL (2002) Progestin-induced apoptosis in the Macaque ovarian epithelium: differential regulation of transforming growth factor-beta. J Natl Cancer Inst 94: $50-60$

Rodriguez GC, Walmer DK, Cline M, Krigman H, Lessey BA, Whitaker RS, Dodge R, Hughes CL (1998) Effect of progestin on the ovarian epithelium of macaques: cancer prevention through apoptosis? J Soc Gynecol Investig 5: $271-276$

Sit AS, Modugno F, Weissfeld JL, Berga SL, Ness RB (2002) Hormone replacement therapy formulations and risk of epithelial ovarian carcinoma. Gynecol Oncol 86: 118-123

USPSTF (2005) Hormone therapy for the prevention of chronic conditions in postmenopausal women: recommendations from the US. Preventive Services Task Force. Ann Intern Med 142: 855-860

Weiss NS, Hill DA (1996) Postmenopausal estrogens and progestogens and the incidence of gynecologic cancer. Maturitas 23: 235-239

Weiss NS, Lyon JL, Krishnamurthy S, Dietert SE, Liff JM, Daling JR (1982) Noncontraceptive estrogen use and the occurrence of ovarian cancer. J Natl Cancer Inst 68: 95-98

Whittemore AS, Harris R, Itnyre J (1992) Characteristics relating to ovarian cancer risk: collaborative analysis of 12 US case-control studies. II. Invasive epithelial ovarian cancers in white women. Collaborative Ovarian Cancer Group. Am J Epidemiol 136: 1184-1203 